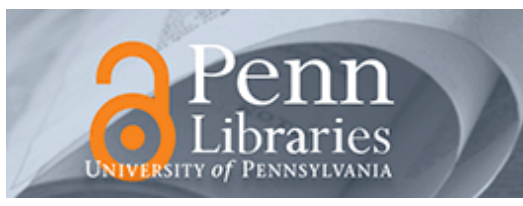

University of Pennsylvania ScholarlyCommons

Wharton Pension Research Council Working Papers

Wharton Pension Research Council

2-1-2001

\title{
Retirement Investing: A New Approach
}

Zvi Bodie

Boston University, zbodie@bu.edu

Follow this and additional works at: https://repository.upenn.edu/prc_papers

Part of the Economics Commons

Bodie, Zvi, "Retirement Investing: A New Approach" (2001). Wharton Pension Research Council Working Papers. 465.

https://repository.upenn.edu/prc_papers/465

This paper is posted at ScholarlyCommons. https://repository.upenn.edu/prc_papers/465

For more information, please contact repository@pobox.upenn.edu. 


\title{
Retirement Investing: A New Approach
}

\begin{abstract}
This paper proposes a new approach to investing for retirement that takes advantage of recent market innovations and advances in finance theory to improve the risk/reward opportunities available to individual investors before and after retirement. The approach introduces three new elements: 1 . It uses inflationprotected bonds to hedge a minimum standard of living after retirement; 2 . It takes account of a person's willingness to postpone retirement, and 3. It uses option "ladders" to lever growth in retirement income.
\end{abstract}

\section{Disciplines}

Economics 


\title{
Retirement Investing: A New Approach
}

\author{
Zvi Bodie
}

PRC WP 2001-8

February 2001

\section{Pension Research Council Working Paper}

\author{
Pension Research Council \\ The Wharton School, University of Pennsylvania \\ 3641 Locust Walk, 304 CPC \\ Philadelphia, PA 19104-6218 \\ Tel: (215) 898-0424 • Fax: (215) 898-0310 \\ http://prc.wharton.upenn.edu/prc/prc.html
}

Pension Research Council Working Papers are intended to make research findings available to other researchers in preliminary form, to encourage discussion and suggestions for revision before final publication. Opinions are solely those of the authors. 


\title{
Retirement Investing: A New Approach
}

\author{
Draft: February 6, 2001
}

\begin{abstract}
This paper proposes a new approach to investing for retirement that takes advantage of recent market innovations and advances in finance theory to improve the risk/reward opportunities available to individual investors before and after retirement. The approach introduces three new elements:
\end{abstract}

- It uses inflation-protected bonds to hedge a minimum standard of living after retirement.

- It takes account of a person's willingness to postpone retirement.

- It uses option "ladders" to lever growth in retirement income.

Zvi Bodie

Boston University School of Management

595 Commonwealth Avenue

Boston, MA 02215

Tel. 6173534160

Email zbodie@bu.edu 


\section{Retirement Investing: A New Approach}

\section{By Zvi Bodie}

\section{Introduction}

Millions of people around the world today are relying on self-directed investment accounts (e.g., IRAs and 401k plans) to provide future retirement income. Since many of these people lack knowledge about how to invest the money accumulating in these accounts, they are seeking the guidance of experts. The advice currently provided by the investment industry, by financial planners, and by government is based upon Markowitz (1952). ${ }^{1}$ The inputs to the Markowitz portfolio-selection model are a set of risky assets characterized by their means, standard deviations, and correlations. The outputs are in the form of a menu of risk-return choices arrayed along an "efficient portfolio frontier."

Since Markowitz introduced his model there have been many extensions and enhancements in the scientific literature. For our purposes the most important theoretical development has been Merton (1969, 1971, 1975, 1992). He showed that hedging can be as important as diversifying in the demand for assets. The desire to hedge against a risk gives rise to a demand for securities that are highly correlated with that risk. For example, a desire to hedge against adverse changes in short-term interest rates induces a demand for long-term bonds.

The 1970s, 80s, and 90s saw major market innovations and the rise of the new field of financial engineering. ${ }^{2}$ The innovations discussed in this paper are inflation-indexed Treasury securities and long-dated index options.

This paper suggests ways to take full advantage of these theoretical advances and market innovations to improve the risk/reward opportunities available to individuals in self-directed retirement accounts. First, it suggests hedging with inflation-protected bonds and annuities as the way to guarantee a minimum standard of living in retirement. Second, it suggests assessing investors' willingness to postpone retirement in determining their optimal asset allocation. Third, it suggests a way to use call options to lever potential income gains while protecting one's minimum standard of living.

\footnotetext{
${ }^{1}$ There is no risk-free asset in Markowitz' model. Tobin (1958) added a risk-free asset to the list of inputs and showed how this expanded the efficient frontier and simplified the process of finding the optimal mix.
} 
The next three sections of the paper deal with each of these items, and a final section offers concluding comments.

\section{Guaranteeing a Minimum Standard of Living in Retirement}

Financial advisors seem to agree that the ultimate goal of a retirement plan is to maintain one's standard of living in retirement. For example, Financial Engines, a popular online source of retirement investing advice, tells its clients:

"Many financial planners estimate that you'll need about $70 \%$ of your preretirement household income (the amount you're making the year before retirement) to maintain your standard of living. This is the amount we use as your default desired income goal."

Financial Engines further distinguishes between this "desired" or "ideal" retirement income goal and a minimum income goal in the following words:

"Your ideal goal is the amount of annual pre-tax income you would like to have in retirement.... Your minimum income goal is the smallest amount you would find acceptable to live on...."

Using Monte Carlo methods, Financial Engines computes a portfolio allocation and a suggested retirement age that enable the user to achieve the minimum income goal with a probability of $95 \%$.

But if your minimum income goal is truly "the smallest amount you would find acceptable to live on," it seems to me that you would want to guarantee it. To that end, this paper proposes hedging with inflation-protected bonds. The concept of eliminating risk by hedging with fixed-income securities is well understood in the context of institutional investing, where it is called "immunization."

\footnotetext{
${ }^{2}$ For a review and discussion of these innovations, see Bodie (1999).
} 
There is an important distinction between hedging and diversifying. ${ }^{3}$ Hedging eliminates the risk of loss by sacrificing the potential for gain. Investing in a risk-free asset is the simplest form of hedging. ${ }^{4}$

In the past there were no fixed-income securities offering long-run protection against the risk of inflation. However, the situation has changed in recent years. Economists from all ends of the ideological spectrum have long urged their governments to issue inflation-indexed bonds to provide a long-run inflation hedge for households saving for retirement. $^{5}$ Until the $1980 \mathrm{~s}$, however, no government of a major industrialized country was willing to do so. Then in 1981 the government of the UK started issuing inflationindexed gilts (i.e., bonds) with the stated goal of providing a means for pension funds to hedge retirement benefits that were indexed to the cost of living. ${ }^{6}$ The government of Canada followed the lead of the UK in 1994, and in 1997 so did the US Treasury.

The inflation-indexed bonds issued by the US Treasury can be "stripped" by qualified financial institutions to provide a complete array of CPI denominated pure discount bonds with maturities up to 30 years. $^{7}$ Suppose that a single man is 55 years old and plans to retire at age 65. By investing in inflation-protected bonds of appropriate maturities, he can fully immunize a stream of real retirement income (in terms of the CPI) starting at age 65 and ending at age $85 .^{8}$

To guarantee a minimum level of real retirement income for life, people would have to be able to buy inflation-protected life annuities. In the United States (and some other countries) Social Security retirement benefits take the form of inflation-protected life

\footnotetext{
${ }^{3}$ Merriam-Webster's New Collegiate Dictionary, http://www.m-w.com/cgi-bin/dictionary, offers the following definitions: To hedge - to protect oneself from losing by a counterbalancing action; To diversify - to balance defensively by dividing funds among securities of different industries or of different classes."

${ }^{4}$ Bodie and Merton (2000) further distinguish between hedging and insuring. Insuring entails paying a premium to eliminate risk while retaining much of the potential for gain.

${ }^{5}$ Private-sector borrowers with the highest credit ratings have historically been reluctant to issue bonds that are indexed to the cost of living.

${ }^{6}$ Specifically these bonds are indexed to the RPI, the UK equivalent of the CPI, with an adjustment lag of 6 months.

${ }^{7}$ In 1998 the U.S. Treasury also started issuing 30-year inflation-indexed savings bonds - called I-bonds. I-bonds offer additional benefits: (1) the holder can cash them in early at their accrued value, thereby avoiding a potential capital loss if real interest rates rise, (2) interest earnings are not taxed until the bonds are cashed, thereby making them suitable investments even outside of tax-advantaged accounts.
} 
annuities, but Social Security benefits may fall short of a person's minimum desired level of real retirement income. Private annuity companies can fill the gap, using inflationprotected bonds to immunize their liabilities. ${ }^{9}$

Another major threat to a person's standard of living in retirement is failing health and disability in the later years. In the U.S., expensive new medical procedures have prolonged the lives of elderly people suffering from serious illnesses. As a by-product, these procedures have increased the cost of living in the retirement years. Investing in an apartment in an "assisted-living" facility after retirement is likely to become an attractive alternative for increasing numbers of people. ${ }^{10}$

\section{Taking Account of a Flexible Retirement Age}

Recent theoretical literature has explored the relationship between optimal investing and the flexibility a person has in choosing how much to work. ${ }^{11}$ The theory suggests that the effect of labor supply flexibility on the optimal portfolio mix can be quite large. ${ }^{12}$ It therefore makes sense to incorporate this effect in applied models of retirement investing.

To illustrate, consider a person saving for retirement with a fixed saving rate and a predictable salary until retirement. Her "risk-free" retirement age based on earning the risk-free rate of interest (3.5\% per year) is 65 . By choosing to invest some of her retirement fund - say 50\% — in stocks, her future rate of return becomes risky. If the expected rate of return on stocks exceeds the risk-free interest rate by $4 \%$ per year, her reward is an expected retirement age of 61. But there is a risk of her having to postpone retirement past age 65. The standard deviation of her retirement age is 3 years.

Figure 1 illustrates the tradeoff between risk and reward in terms of expected retirement age and its standard deviation. It shows the results of Monte Carlo simulations

\footnotetext{
${ }^{8}$ For people whose consumption spending differs significantly from that used in the CPI, there will still be "basis" risk. However studies have shown that the CPI tracks the cost of living for the typical retiree reasonably well.

${ }^{9}$ Lincoln National Insurance Company offers inflation protected immediate annuities. http://www.annuitynet.com/products/individual/inflation/index.asp.

${ }^{10}$ Bodie, Hammond, and Mitchell (2001).

${ }^{11}$ See Bodie, Merton, and Samuelson (1992).

${ }^{12}$ See Viceira (2001).
} 
generated assuming that stock returns are lognormally distributed with a mean risk premium of $4 \%$ per year and annualized standard deviation of $20 \%$.

Figure 1. Retirement-Age Risk and Reward

a. $50 \%$ in stocks

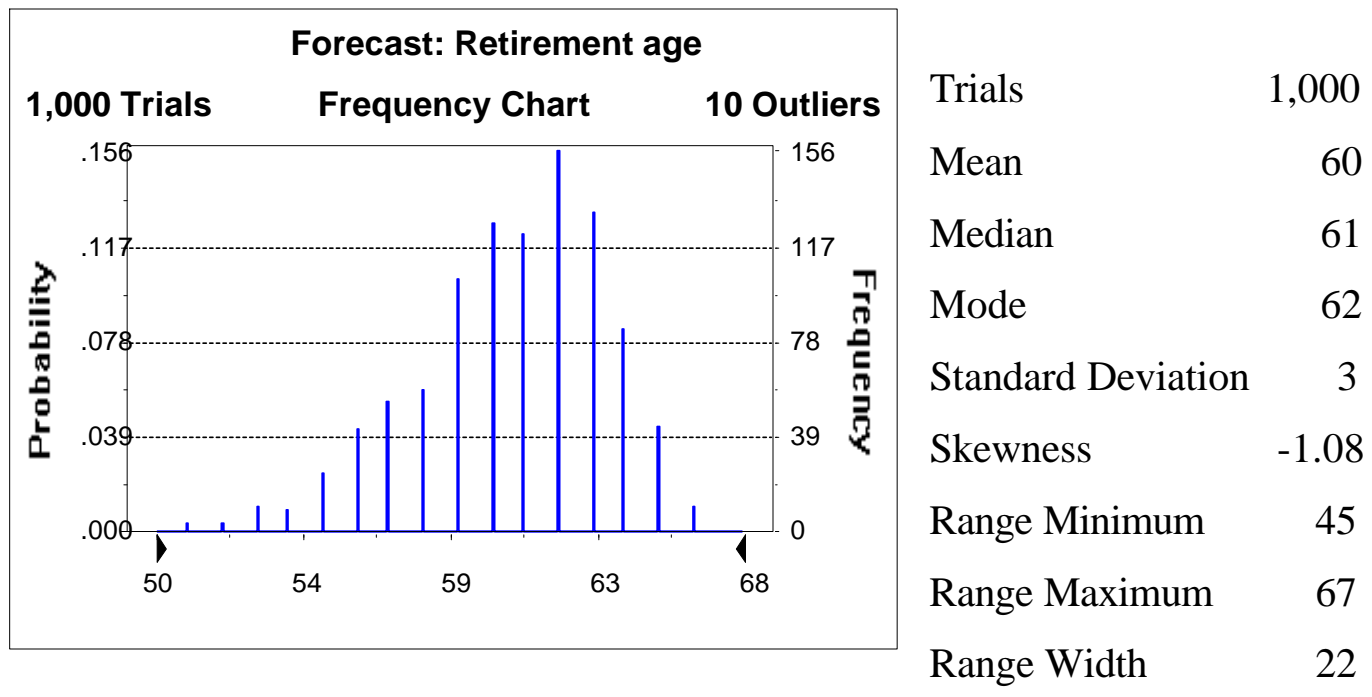

b. $100 \%$ in stocks

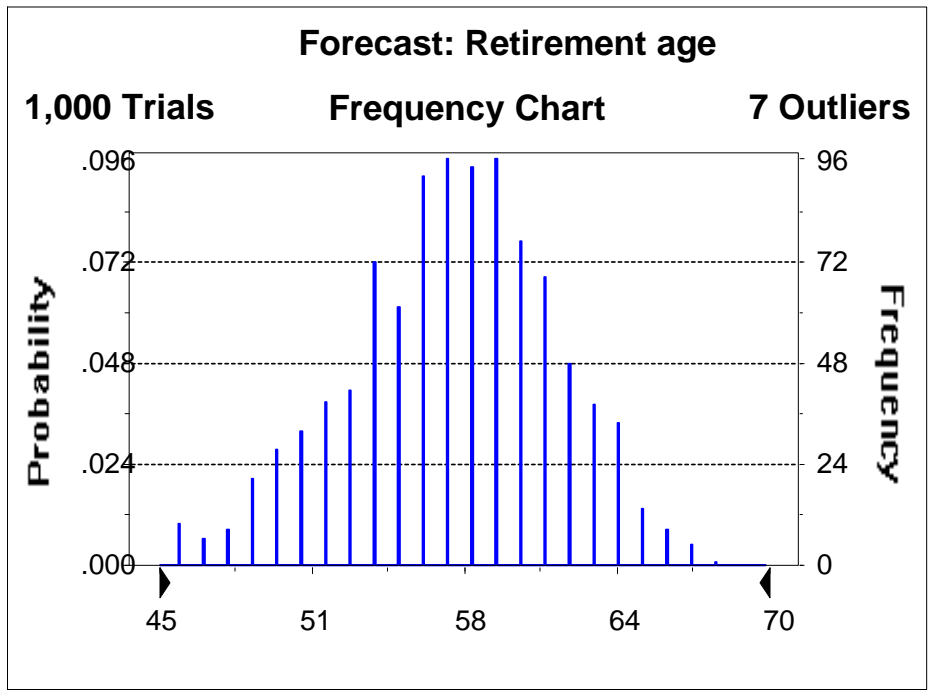

Trials

Mean

Median

Mode

57

Standard Deviation $\quad 4$

Skewness

$-0.35$

Range Minimum 41

Range Maximum 68

Range Width

27

The higher the fraction invested in stocks, the lower the expected retirement age and the higher the standard deviation. By increasing the proportion invested in stocks from $50 \%$ to $100 \%$, the expected retirement age drops to 57 , and the standard deviation rises to 
4 years. The more willing the investor is to postpone retirement, the higher the fraction he or she should invest in stocks.

\section{Options and Leverage}

Adding index options to the set of portfolio inputs greatly enhances the menu of risk/return opportunities available to investors. Call options allow investors to leverage potential gains while insuring that their minimum income is secure. ${ }^{13}$ To illustrate the principle, compare the following investment strategies for a $\$ 1$ million investment over the next year:

(1) Invest all \$1 million in 1-year risk-free bonds to earn 5\%.

(2) Invest all \$1 million in an equity index fund.

(3) Invest $\$ 900,000$ in 1-year risk-free bonds to earn $5 \%$ and the other $\$ 100,000$ in the index fund.

(4) Invest $\$ 900,000$ in 1-year risk-free bonds to earn 5\%, and the other $\$ 100,000$ in a 1year call option on that same index with an exercise price equal to the current value of the index.

Figure 2 contrasts the payoffs from the four strategies. Note that the payoff diagram for the options strategy has a "kink" at the exercise price of 100. The payoff diagrams for the other three strategies are all straight lines starting at the vertical axis.

\footnotetext{
${ }^{13}$ For additional papers on this subject see Merton et al (1978), Bodie and Crane (1999), and Bodie (2001).
} 
Figure 2. Comparison of Four Investment Strategies

\section{Payoff Diagrams}

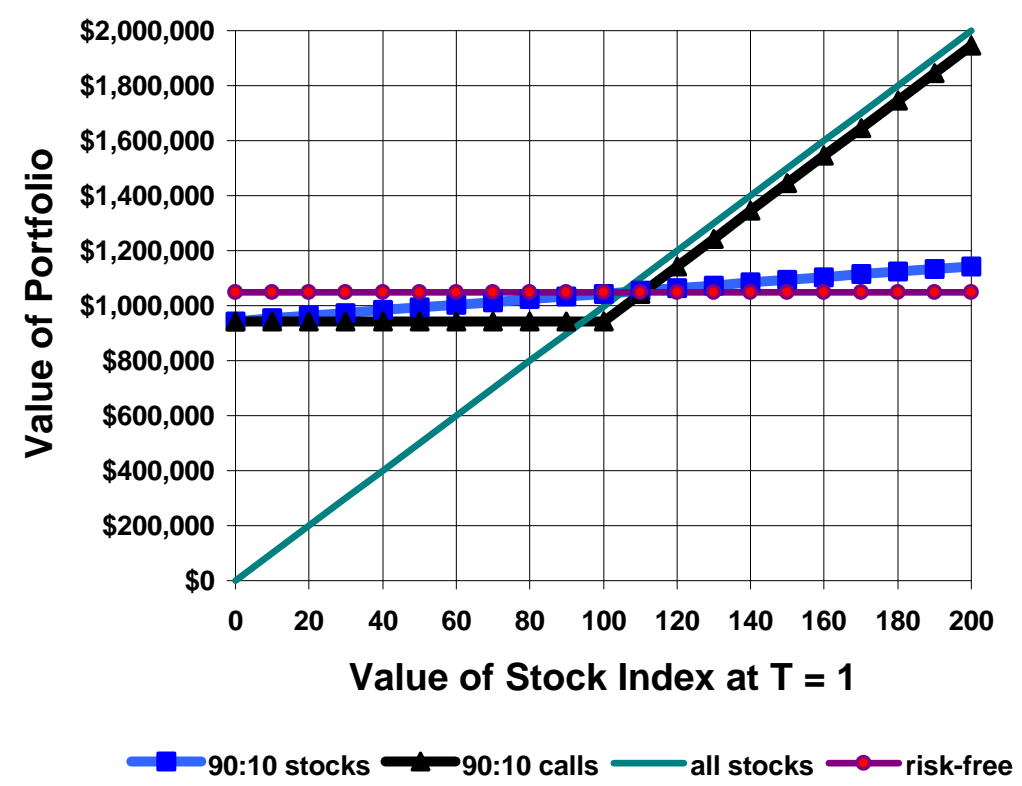

Now compare the two 90:10 strategies. The worst-case outcome for both strategies is a portfolio value of $\$ 945,000$. In this sense both strategies provide "downside" protection when compared with the all-stocks strategy. The call-option strategy, however, has a payoff diagram with a steeper slope to the right of the kink. Thus, the 90:10 call-option strategy has more "upside leverage" than the 90:10 stocks strategy. ${ }^{14}$

The exercise price of the option determines the threshold value of the market index, that is, the value of the index that must be reached in order for the call option to have a positive payoff at expiration. The higher the threshold, the lower the cost of each option, and the steeper the slope to the right of the kink. ${ }^{15}$

\footnotetext{
${ }^{14}$ In our example, its slope is the same as the payoff line for the all-stocks strategy.

${ }^{15}$ Equation 1 expresses the basic formula that relates the investor's wealth to the value of the stock index on the option's expiration date and to the exercise price, $X$ :

$\frac{W_{1}}{W_{0}}=.9 e^{.05}+\frac{.1}{C(X, 1)} \max \left[100 \frac{S_{1}}{S_{0}}-X, 0\right]$

where: $W_{T}$ is the investor's wealth at time $T$

$r$ is the risk-free interest rate

$C(X, T)$ is the price of a call with exercise price $X$ expiring at time $T$

$S_{T}$ is the value of the reference index at time $T$
} 
Figure 3 shows the investor's payoff as a function of the value of the stock index for three different exercise prices: 100,120 , and 140 . The minimum value of the portfolio is the same in all three cases: $\$ 945,000$; however the higher the exercise price, the steeper the slope to the right of its kink.

Figure 3. Effect of Changing the Option's Exercise Price

\section{Payoff Diagrams}

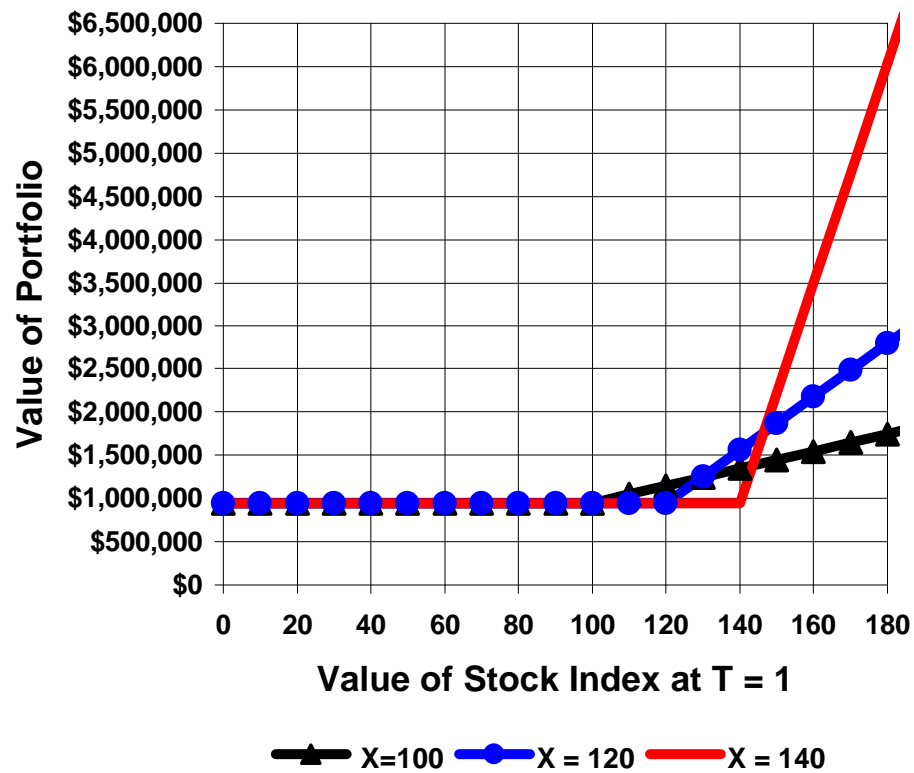

In practice, instead of having all options mature in a single year, the investor can buy a series of call options maturing over several years. When applied to bonds of different maturities, such a strategy is called "laddering." Accordingly, I call this strategy laddering of options.

Currently exchange-traded SPX LEAPS have maturities as long as three years. Firms that sell structured equity participation securities have issued notes with maturities of 10 years. It is not hard to imagine that innovative firms might issue long-dated index call options or even option "ladders." 


\section{Conclusions}

Millions of people today are relying on self-directed investment accounts to provide future retirement income. Investment firms, financial planners, and government agencies all advise these people to hold their retirement funds in diversified portfolios with a large fraction in stocks. This paper has proposed several ways to improve the risk/reward opportunities available to these individuals. I summarize them here in the form of concrete proposals:

First, to enable participants in employer-sponsored 401k-type plans to hedge minimum levels of retirement income, employers should offer inflation-protected annuities in the plan.

Second, advisors should explicitly take account of the individual's willingness to postpone retirement in suggesting an optimal asset allocation. The greater the willingness to continue working past the expected retirement date, the greater the proportion to invest in stocks.

Third, sponsors of self-directed investment plans can enhance the risk-reward opportunities available to investors by offering option-like securities or contracts as an additional asset class. These assets can provide a means of leveraging participation in stock market gains while protecting one's minimum standard of living. 


\section{References}

Bodie, Z. 1999. "Investment Management and Technology: Past, Present, and Future," in BrookingsWharton Papers on Financial Services, Washington, DC: Brookings Institution Press.

2001. "Financial Engineering and Social Security Reform," chapter 8 in Risk Aspects of Investment-Based Social Security Reform, edited by John Campbell and Martin Feldstein, Chicago, IL: University of Chicago Press.

and D.B. Crane. 1999. "The Design and Production of New Retirement Savings Products," Journal of Portfolio Management, vol. 25 No. 2, (Winter): 77-82. Reproduced as chapter 8 in Bodie and Davis (2000).

Publishing.

, and E.P. Davis. 2000. The Foundations of Pension Finance. London, UK: Edward Elgar

, B. Hammond, and O. S. Mitchell. 2001. Innovations for Managing the Risks of Retirement,

Philadelphia, PA: University of Pennsylvania Press, forthcoming.

, and R.C. Merton. 2000. Chapter 10 in Finance, Upper Saddle River, NJ: Prentice Hall.

, R.C. Merton, and W. Samuelson. 1992. "Labor Supply Flexibility and Portfolio Choice in a Life Cycle Model," Journal of Economic Dynamics and Control. Vol. 6: 427-449.

Markowitz, H. 1952. "Portfolio Selection.” Journal of Finance, vol. 7 (March): 77-91.

Merton, R.C. 1969. "Lifetime Portfolio Selection Under Uncertainty: The Continuous-Time Case." Review of Economics and Statistics, 51 (August): 247-57. Reproduced as chapter 4 in Merton (1992).

1971. "Optimum Consumption and Portfolio Rules in a Continuous-Time Model." Journal of Economic Theory, 3 (December): 373-413. Reproduced as chapter 5 in Merton (1992).

1975. "Theory of Finance from the Perspective of Continuous Time," Journal of Financial and Quantitative Analysis, 10 (November): 659-74.

1992. Continuous-Time Finance, Revised edition, Oxford: Basil Blackwell.

M.S. Scholes, and M. Gladstein. 1978. "The Returns and Risk of Alternative Call Option

Portfolio Investment Strategies," Journal of Business, 51 (April): 183-242.

Tobin, J. 1958. "Liquidity Preference as Behavior Towards Risk.” Review of Economic Studies. vol.25 (February): 68- 85.

Viceira, L. 2001. "Optimal Portfolio Choice for Long-Horizon Investors with Non-tradable Labor Income," Journal of Finance, forthcoming. 